\title{
Pheromonal effects on germ cells of house mouse males: possible evolutionary consequences
}

\author{
Eugene Daev \\ Department of Genetics and Biotechnology, Faculty of Biology, \\ Saint Petersburg State University, Universitetskaya nab., 7-9, Saint Petersburg, \\ 199034, Russian Federation \\ Address correspondence and requests for materials to Eugene Daev, \\ e.daev@spbu.ru,mouse_gene@mail.ru
}

\begin{abstract}
It is well known that in mice some pheromones modify reproductively important features. But the genetic mechanisms underlying such changes remain insufficiently studied. Here we show that in laboratory mice (Mus musculus L.), volatile signal 2,5-dimethylpyrazine excreted by donor stressed females increases the level of structural chromosome aberrations and other meiotic disturbances in spermatocytes of recipient males after nasal contact with the volatiles via sniffing. These chemosignals (i.e. pheromones) also induce abnormalities of sperm heads in the recipient mice. We assume that visible macro-damages at the chromosome level in meiotic cells are marks of a more widely disturbing effect (not only macro- but also micro-damages) of some olfactory signals in meiotic cells. It is most probable that the effects of volatile cues are mediated by the nervous system of the recipient organism. While gross chromosomal aberrations lead mainly to death of damaged cells, some of them (micro-damages of the chromosomes) might reach spermatozoa, and we detected part of them as anomalous sperm heads. Such abnormalities can reduce the fertilizing capacity of sperm. Moreover, some of the mutations induced by density-dependent volatile chemosignals can reach the progeny and influence the quantity and genetic quality of future generations. Possible microevolutionary consequences are discussed.
\end{abstract}

Keywords: abnormal sperm heads, chromosome aberrations, house mouse, microevolutionary consequences, pheromones, spermatocytes.

Citation: Daev, E. 2019. Pheromonal effects on germ cells of house mouse males: possible evolutionary consequences. Bio. Comm. 64(2): 158-165. https://doi. org/10.21638/spbu03.2019.207

Author's information: Eugene Daev, Dr. of Sci. in Biology, Professor, orcid.org/00000003-2036-6790

Manuscript Editor: Anton Nizhnikov, Department of Genetics and Biotechnology, Faculty of Biology, Saint Petersburg State University, Saint Petersburg, Russia

Received: May 6, 2019;

Revised: June 24, 2019;

Accepted: June 24, 2019;

Copyright: (c) 2019 Daev. This is an open-access article distributed under the terms of the License Agreement with Saint Petersburg State University, which permits to the authors unrestricted distribution, and self-archiving free of charge.

Funding: No funding information provided.

\section{Introduction}

Consequences of between- and within-individual variation in the genomic stability of germ cells induced by environmental factors still remain insufficiently studied. Even less is known about the zoosocial factors which bring about such genetic variation. Meanwhile, induced changes in the genome of germ cells are the basis for the future microevolutionary events.

In mice and other small rodents some communicative chemosignals (i. e., pheromones) can act as stressors and hence have a mutagenic effect. They destroy the genomic integrity in somatic cells as well as germ cells (Daev, 1994, 2007, 2010). Most of the well-known pheromone effects in mice and other animals are signalling or primer changes (behavioural, hormonal, or even morphological) at the level of the whole recipient organism (Koyama, 2004; Tirindelli et al., 2009). Some previously described pheromone-induced alterations are connected with the reproductive function of animals (Bronson and Coquelin, 1980; Vandenbergh, 1983). It has been shown that conspecific donor pheromones induce "negative" effects mainly in same-sex recipients but act in a "positive" manner in animals of the opposite sex (Koyama, 2004). Small volatiles from unfamiliar 
male mouse urine induce a block of pregnancy (Bruce, 1959; Peele et al., 2003). There are some results also that male urinary $17 \beta$-oestradiol is absorbed by pregnant females and influences blastocyst implantation directly in the endometrium (Guzzo et al., 2012). That is consistent with previous data indicating steroid dependency of the effect (Rajendren and Dominic, 1988). Chemical cues excreted in the urine of adult male prairie deer mice (Peromyscus maniculatus bairdii) inhibit growth of the testes and seminal vesicles of juvenile conspecifics (Lawton and Whitsett, 1979). At the same time, conspecific odors of the opposite sex donors are rather inductive (for example, the Vandenbergh effect) with respect to reproductive function in mice (Koyama, 2004). Nevertheless, the natural pheromone 2,5-dimethylpyrazine, which is produced by grouped mouse females in their urine only at high density, or when present synthetically, delays puberty of growing house mice of both sexes. The excretion of 2,5-dimethylpyrazine (DMP) in mouse urine is adrenal dependent (Ma et al., 1998). In CBA mice it has been shown that tester males and females avoid DMP in a T-maze (Daev et al., 2007). Smelling DMP also induces immune suppression in mice: the quantity of antibody-producing cells is reduced as under physical stress, and the chromosome aberration level in bone marrow dividing cells is increased (Daev et al., 2007a). All these data, together with the DMP-dependent inhibition of reproduction (Daev, 2003), indicate the action of the pheromone as a powerful stressor in mice. It is suggested that 2,5-dimethylpyrazine (DMP) inhibits the maturation of juvenile mice in a population and may function when the living conditions are below the optimal level for reproduction (Jemiolo and Novotny, 1994). These changes, if they occur in a wild population, can influence its density and structure. Some of the changes, such as puberty delay and acceleration in feral populations of house mouse by female/ male urinary cues, were shown by Massey and Vandenbergh (1980, 1981). While genetic events undoubtedly underlie the majority of such effects (Brennan and Keverne, 2004), the relationship between a pheromone's influence at the level of the whole organism and at the intracellular changes in somatic and germ cells is poorly understood.

It is well known from Hans Selye's works (1936, 1946) that stress is characterized by drastic neuroendocrine, immunological, morphological and reproductively important changes inside a stressed organism. Therefore, stressors change the homeostasis of the recipient organism and its cells (Cannon, 1935). Numerous primer and releasing effects of some pheromones indicate that they can be considered stress factors in rodents (Daev, 1994, 2007; Koyama, 2004). On the other hand, since the time of Selye, the physiologic hypothesis of mutation has been put forward (Kerkis, 1940; Loba- shev, 1947). According to this hypothesis, disturbance of the physiological balance inside the cell and the whole organism might result in mutational changes.

Here we use a mouse model of olfactory-induced stress to show the relationship between chromosome aberrations at the spermatocyte level, and abnormal sperm heads frequency. Olfactory regulation of genome integrity in germ cells is proposed as one possible mechanism of density-dependent reproductive suppression in the house mouse which could influence microevolutionary events.

\section{Materials and methods}

Material. An inbred CBA/LacStoRap strain of mice (hereinafter referred to as CBA) was obtained from the Rappolovo Laboratory of Animal Breeding, Russian Academy of Medical Sciences. Adult (3-month-old) fertile male mice of the CBA strain were used for the experiments. The animals were treated and housed in accordance with the rules of European Union Guidelines on Animal Research (No. 86/609/EEC) and Rus-LASA (No.1117799015454, 08.08.2011). The study was approved by the Ethics Committee of St. Petersburg State University in the field of animal research. Animals were maintained in vivarium of the Faculty of Biology and Soil Sciences of the Saint Petersburg State University in standard polypropylene cages $(30 \times 20 \times 13 \mathrm{~cm})$ under controlled conditions of temperature $\left(20 \pm 2^{\circ} \mathrm{C}\right)$, humidity and light (12 and $12 \mathrm{~h}$ of light and dark respectively). Sawdust and shavings were used as a bedding material. The animals were given a standard food ration and water ad libitum. Ten days before the experiments, males of the same weight $( \pm 1 \mathrm{~g})$ were grouped by five or six per cage. On the eleventh day groups of males were subjected to particular experimental exposures.

Exposures and sampling procedures. Perforated capsules with filter paper soaked with $1.5 \mathrm{ml}$ of $0.01 \%$ aqueous solution of DMP (Aldirch, 98\%) were placed on the wire mesh cover of corresponding experimental cages. The direct contact with DMP excepting olfactory perception was excluded. When tested for abnormal sperm head frequency (first experiment) tester animals were exposed to daily renewed DMP solution (the same as was mentioned above) for 17 days. The selected duration corresponds to two cycles of the mouse seminiferous epithelium (from spermatocytes to spermatozoa) (Oakberg, 1956, 1957). We believed that during this time enough damages could accumulate to manifest themselves at the level of the sperm head morphology. Two independent replicas of the first experiment with an interval of more than one month were conducted.

In a second experiment tester-males were exposed to the pheromone for $24 \mathrm{hrs}$. After that the material was fixed for further spermatocyte analysis. 
In both experiments identical capsules with the same amount of distilled water were used for control groups. To synchronize the experiments the single exposure for $24 \mathrm{hrs}$ in the second experiment was conducted in parallel with the last exposure on the $17^{\text {th }}$ day of the first experiment ( $2^{\text {nd }}$ replica). For the spermatocyte analysis and sperm head abnormalities test (SHAT) all animals were killed simultaneously by neck dislocation $24 \mathrm{hrs}$ or on the $18^{\text {th }}$ day after the beginning of the exposure with DMP, correspondingly.

We predicted that primary spermatocytes, at the diakinesis stage and during subsequent meiotic divisions, are sensitive to sharp hormonal imbalance during stress-response. There are also data which suggest spermatocytes of rats and mice at diakinesis-metaphase I stage are sensitive to some chemical substances (Brook and Chandley, 1986; Lahdetie et al., 1997).

For the SHAT, sperm were collected from caudal epididymides on the $18^{\text {th }}$ day after the beginning of the experiment. In accordance with the duration of mouse spermatogenesis, this period is needed for primary spermatocytes to differentiate into mature spermatozoa and reach caudal epididymis (Adler, 2000). Epididymides were excised and minced in isotonic saline solution and the suspension was filtered to remove pieces of tissue. The diluted suspension was smeared on slides (Wyrobek and Bruce, 1978). After drying at room temperature for 2-3 days slides were stained with freshly filtered $4 \%$ acetic orcein stain.

For the cytogenetic analysis of primary spermatocytes at the metaphase I stage and spermatocytes II at the ana-telophase stage, testes were removed 24 hours after the beginning of exposure. Squashed slides were prepared by the standard method (Page et al., 1998) with our modifications. Pieces of seminiferous tubules were gently minced with tweezers and then treated in hypotonic solution $\left(0.56 \% \mathrm{KCl}, 37^{\circ} \mathrm{C}, 6-10 \mathrm{~min}\right)$ and fixed in Clarke's fluid ( 3 parts absolute ethanol: 1 part glacial acetic acid). The fixed material was stored at $4^{\circ} \mathrm{C}$ until analysis. For the temporary slides' preparation extra liquid was removed with filter paper and slides with the material were stained with fresh $4 \%$ Giemsa or filtered $4 \%$ acetic orcein stain. Then extra stain was removed with filter paper and the pieces were squashed under a cover slip in a drop of $45 \%$ acetic acid. This allowed us to obtain a sufficient number of metaphase and ana-telophase spreads suitable for the analysis without using colchicine. Slides were analysed immediately with a Jenaval or AxioScope A1 microscope under 1000 magnification.

In both experiments, germ cells of the mouse males at the beginning of the exposure were at the sensitive stages of differentiation.

Assessment of samples and statistics. For SHAT at least 500 spermatozoids with intact tail threads were analyzed per animal. Different types of head abnormali- ties (banana-shaped, amorphous, without hook, threadlike and others) were determined (Wyrobek and Bruce, 1978; Koch et al., 1989; Amer et al., 2003).

For spermatocyte analysis, at least 75 well-spread metaphase I plates or ana-telophases II per animal were analyzed. Disturbances such as different multivalent associations, autosomal univalents and isochromatid fragments were taken into account (Amer et al., 2012) for the metaphase analysis. At ana-telophase II stage the frequency of bridges and fragments was calculated.

For small samples it is difficult to correctly determine the type of distribution, so we used nonparametric tests to analyze the results. To estimate the homogeneity of the results inside variants and the difference between variants, the analysis of the Chi-square contingency tables was used (or Fisher's exact test for small samples). Statistical analysis of data was performed using GraphPad software version 4.00 (GraphPad Software, San Diego California, USA). For better presentation total frequencies of corresponding disturbances for each group were calculated.

\section{Results}

\section{SPERM HEAD ABNORMALITIES}

No significant individual variability was discovered. The homogeneity of data obtained allowed us to merge them inside and between groups of CBA males of corresponding variants (Chi-square test, $\mathrm{df}=5 ; \mathrm{P} \geq 0.3$ ). There were no differences between the first and second replicas of the first experiment (Chi-square test, $\mathrm{df}=1, \mathrm{P} \geq 0,58$ ). Therefore, the respective data have been combined also (Table 1). Altogether, the two control groups and two experimental groups of animals included 24 animals.

It was shown that daily exposure to DMP for 17 days increased the total frequency of sperm head abnormalities in males by 1.7 times in comparison with the level in control animals. Because the data met the conditions of normality according to Kolmogorov-Smirnov (but no more precise other criteria), for better clarity, the values of mean, standard deviation (95\%SD) and confidence interval $(99 \% \mathrm{CI})$ are given. (Table 1$)$. The effect of DMP is comparable with the genotoxic effect of crotonaldehyde (CAS No. 123-73-9, MW 70.09, molecular formula $\mathrm{C} 4 \mathrm{H} 6 \mathrm{O})$ on the $21^{\text {st }}$ day after single intraperitoneal injection of $8 \mu \mathrm{l} / \mathrm{kg}$ b.w. in male Swiss albino mice (Jha and Kumar, 2006).

Spectrum analysis showed that in the control group, variant portions of amorphous heads and abnormal hooks among abnormal spermatozoids accounted for $55 \%$ and $29 \%$, respectively. The fraction of tread-like and banana-like heads was $11 \%$ and the rest (minor part) of other types of abnormalities accounted for $5 \%$. After the exposure to DMP, the spectrum of abnor- 
Table 1. Total frequency of abnormal sperm heads in caudal epididymis of CBA males after exposure with 2,5-dimethylpyrazine

\begin{tabular}{c|c|c|c|c}
\hline Variant & $\begin{array}{c}\text { Number } \\
\text { of } \\
\text { animals }\end{array}$ & $\begin{array}{c}\text { Number of } \\
\text { analyzed } \\
\text { spermatozoids }\end{array}$ & $\begin{array}{c}\text { Number of } \\
\text { abnormal } \\
\text { sperm } \\
\text { heads }\end{array}$ & $\begin{array}{c}\text { Frequency } \\
\text { of abnormal } \\
\text { sperm heads } \\
(\%)\end{array}$ \\
\hline \multicolumn{2}{c}{$1^{\text {st }}$ trial }
\end{tabular}

\begin{tabular}{l|l|l|l|l}
\hline Control & 6 & 3000 & 141 & 4,70 \\
\hline DMP & 6 & 3000 & 223 & $7,43^{*}$ \\
\hline \multicolumn{4}{c}{$2^{\text {nd }}$ trial }
\end{tabular}

\begin{tabular}{l|l|l|l|l}
\hline Control & 6 & 3000 & 131 & 4,37 \\
\hline DMP & 6 & 3000 & 228 & $7,60 *$ \\
\hline
\end{tabular}

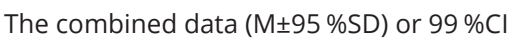

\begin{tabular}{l|c|c|c|c}
\hline Control & 12 & 6000 & 272 & $\begin{array}{c}4,53(4,5 \pm 0,36) \\
4,24,54,9\end{array}$ \\
\hline DMP & 12 & 6000 & 451 & $\begin{array}{c}7,52(7,5 \pm 0,53) \\
7,17,58,0\end{array}$ \\
\hline
\end{tabular}

Note: DMP - exposure with 0,01\% water solution of 2,5-dimethylpyrazine; * - significant differences (Chi-square test, $\mathrm{P}<0,0001$ ).

malities changed: the portion of abnormal sperm with amorphous heads (66\%) was higher (Fisher's exact test, $\mathrm{P}=0.0027)$ and with hook anomalies $(18 \%)$ was lower (Fisher's exact test, $\mathrm{P}=0.0011$ ) than in controls. The reasons for such changes in the spectrum remain to be resolved. No other differences in the spectra of abnormalities among variants were found.

\section{MEIOTIC DISTURBANCES IN SPERMATOCYTES}

There were no differences between animals within corresponding groups during cytogenetic analysis of primary spermatocytes (Chi-square test, $\mathrm{df}=5, \mathrm{P} \geq 0.63$ ). Therefore, the data obtained were merged inside each group. The exposure of mouse males to DMP for $24 \mathrm{hrs}$ elevated the total frequency of meiotic disturbances by 2.1 times compared to the control level (Table 2). No differences in the spectrum of aberrations were shown. Among aberrant metaphase plates the frequency of multivalent associations was $21-23 \%$; the rest were autosomal univalents and other rare damages.

Intragroup homogeneity was shown for each variant of both trials (Chi-square test, $\mathrm{df}=4, \mathrm{P} \geq 0.54$ for the first trial and $\mathrm{df}=5, \mathrm{P} \geq 0.64$ for the second trial). Analysis of the frequency of aberrant spermatocytes II in both trials showed consistent results, so the data were joined together. The exposure to DMP for 24 hours significantly increased the level of disturbed ana-telophases II in the mouse male meiosis (Table 3).

Thus, olfactory contact with DMP for 24 hours increases the frequency of meiotic disorders detected in
Table 2. Total frequency of spermatocytes I with chromosomal abnormalities at metaphase I stage in meiosis of CBA males after exposure with 2,5-dimethylpyrazine

\begin{tabular}{l|c|c|c|c}
\hline \multirow{2}{*}{ Variant } & \multirow{2}{*}{$\begin{array}{c}\text { Number of } \\
\text { animals }\end{array}$} & \multicolumn{2}{|c|}{$\begin{array}{c}\text { Number of } \\
\text { spermatocytes I: }\end{array}$} & $\begin{array}{c}\text { Frequency of } \\
\text { abnormal cells, \% }\end{array}$ \\
\cline { 3 - 4 } & normal & abnormal & \\
\hline Control & 6 & 461 & 42 & 8,3 \\
\hline DMP & 6 & 505 & 105 & $17,2^{\star}$ \\
\hline
\end{tabular}

Note: designations are the same as in the table 1.

Table 3. Total frequency of spermatocytes II with chromosomal abnormalities at ana-telophase II stage in meiosis of CBA males after exposure with 2,5-dimethylpyrazine

\begin{tabular}{|c|c|c|c|c|}
\hline \multirow{2}{*}{ Variant } & \multirow{2}{*}{$\begin{array}{l}\text { Number of } \\
\text { animals }\end{array}$} & \multicolumn{2}{|c|}{$\begin{array}{c}\text { Number of } \\
\text { spermatocytes II: }\end{array}$} & \multirow{2}{*}{$\begin{array}{c}\text { Frequency of } \\
\text { abnormal cells, } \\
\%\end{array}$} \\
\hline & & normal & abnormal & \\
\hline
\end{tabular}

\begin{tabular}{l|c|c|c|c}
\hline \multicolumn{5}{c}{$1^{\text {st }}$ trial } \\
\hline Control & 5 & 474 & 3 & 0,63 \\
\hline DMP & 5 & 541 & 13 & $2,35^{*}$ \\
\hline \multicolumn{5}{|c}{$2^{\text {nd }}$ trial } \\
\hline Control & 6 & 762 & 3 & 0,39 \\
\hline DMP & 6 & 521 & 14 & $2,62^{*}$ \\
\hline
\end{tabular}

$\left(1^{\text {st }}\right.$ trial $\left.+2^{\text {nd }}\right)$ trials

\begin{tabular}{l|c|c|c|c}
\hline Control & 11 & 1236 & 6 & 0,48 \\
\hline DMP & 11 & 1062 & 27 & $2,48^{*}$ \\
\hline
\end{tabular}

* — significant differences (Fisher's exact test or Chi-square test for merged data, $\mathrm{P}<0,04)$.

spermatocytes I and II. The frequency of anomalous sperm heads is increased correspondingly by the 18th day after the beginning of the exposure to the pheromone.

\section{Discussion}

Induction of abnormal sperm heads in CBA males after DMP exposure for six days has been reported previously (Daev and Dukelskaya, 2003). In spite of differences in absolute values there and here, the effect was similar: the frequency of abnormalities in treated males was approximately twice that of the control group. Thus, an additional 11 days of exposure does not induce extra morphological abnormalities during the late differentiation stages of the germ cells in males. Probably, these stages are less sensitive to the DMP action or animals have adapted to longlasting exposure to the volatile stressor. The last suggestion is supported by previous data about changes in the 


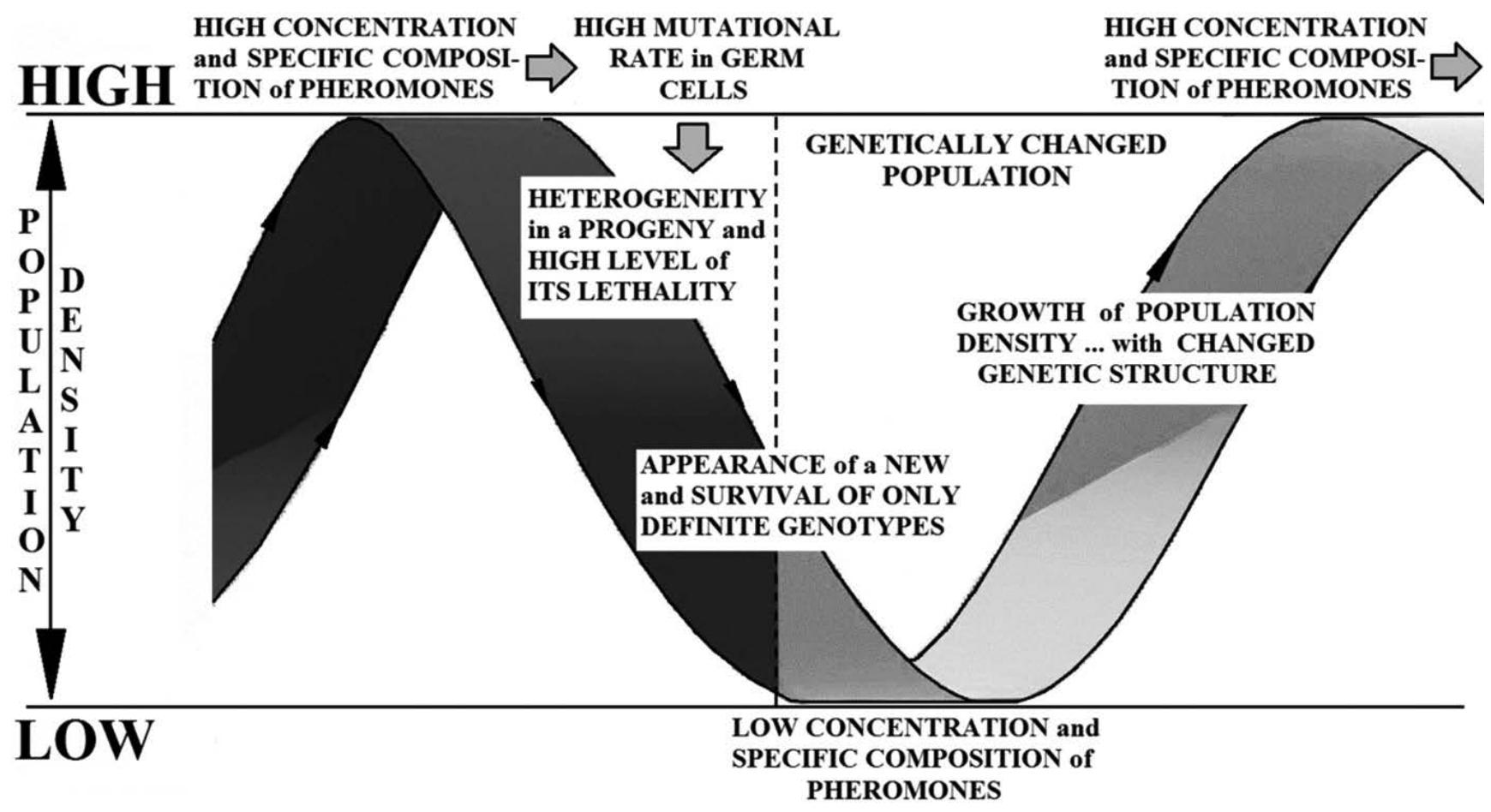

Fig. 1. Proposed mechanism of the induction of genetic heterogeneity in the house mouse populations. It is assumed that some densitydependent pheromonal cues in mice can modulate genetic integrity of male germ cells. Following changes of a quantity and genetic quality of the progeny could serve as a base for the future microevolutionary events.

X-ray-induced level of meiotic disturbances after single or multiple exposures of young CBAB6F1 mouse males to the excretions of adult CBA males (Tzapigina et al., 1981). It has been shown that the stress state induced by pheromones of adult males increases the effect of irradiation. Adaptation to a pheromonal stressor after multiple exposures, vice versa, reduces the damaging action of X-rays (Tzapigina et al., 1981).

The induction of abnormalities in primary spermatocytes obtained here demonstrates that diakinesis and metaphase I are sensitive to the pheromonal treatment. The increased frequency of meiotic abnormalities reflects induced destabilization of the germ cell genome, i.e., mutagenic influence of the volatile stressor (DMP) through changes in the state of the central nervous system of recipient animals. No doubt, the cytogenetically visible macro-damages at the chromosome level are only a part of a wide spectrum of different types of other disturbances. These could be invisible mutations such as microdeletions or single nucleotide changes, etc. (genomic microinjuries). If the macroinjuries are the leading cause of cell death, microinjuries of DNA (if we take into account the duration of germ cell differentiation) can serve as a reason, at least partly, for shape abnormalities of sperm heads and other more delayed damaging effects. Therefore, the increased level of sperm head abnormalities is likely the result of the microdamaging mutagenic action of DMP-induced stress on meiotic spermatocytes.
This is especially important since it is known that DMP and some other pheromonal treatments of the recipient mouse males induce lethality in their progeny after mating with intact females (Daev, 2003, 2008). The reproductive ability of stressed males was checked by mating with intact females 36-42 days after the exposure to pheromones or 18-22 days after the exposure to DMP. All periods between the start of the exposures and mating with intact females were determined according to durations of mouse spermatogenesis (Oakberg, 1956, 1957). The increased lethality level in progeny of the recipients shows sensitivity of the genome of germ cells at definite stages of differentiation to a pheromonal stressor. The induction of lethality in the progeny of DMPtreated mouse males supports the hypothesis that DMPinitiated genetic damages in germ cells of males obtained here are the mechanism of their fertility decline after DMP sniffing at high population density (Daev, 2007).

Therefore, in addition to the well-known pregnancy blocking described by H. Bruce (1959) and other pheromonal effects (Koyama, 2004), we have a newly recognized harmful chain sequence phenomena. Pheromone 2.5-DMP, produced only by overcrowded adult mouse females (Jemiolo and Novotny, 1994) induces:

1) meiotic disturbances in germ cells of the recipient mouse males;

2) sperm head abnormalities in the recipient mouse males, correspondingly, 18 days after the beginning of the treatment; 
3) dominant lethals in the progeny of recipient males, correspondingly, 18-22 days after the beginning of exposure (16).

Evidently, there is an interrelation between an increase in the frequency of meiotic disturbances, abnormally shaped heads of spermatozoids and dominant lethals after pheromonal exposure. This permits us to suggest that damage of the genetic material in germ cells in response to a zoosocial stressor is a primary reason of further reproductively important events (Daev and Dukelskaya, 2005). Induction of chromosomal aberrations and other meiotic disturbances by pheromonal stressors has been shown here for spermatocytes, as well as earlier for spermatogonial cells (Daev, 1983). Pheromones of unfamiliar adult mouse males also induce dominant lethals in the progeny of exposed males (Daev, 1983; Daev et al., 1988). Therefore, data obtained for spermatocytes reflect the mutagenic action of stress induced by some mouse pheromones, and that can be detected as an increased level of abnormal spermatozoa and lethality during corresponding time intervals. The stressor nature of 2,5-DMP action is supported by data about norepinephrine disappearance in one hour after sniffing the substance (Daev et al., 2000) and some other hormonal changes (Glynin, 2018). Similar effects of yet unidentified pheromonal cues from urine of mature mouse males were shown for recipient males of different genotypes such as CBA, CBAB6F1, F1(CBAxCC57Br) (Daev, 1994). But similar cytogenetic effects of DMP were shown for different strains (CBA, BALB/C и $\mathrm{C} 57 \mathrm{BL} / 6$ ) in bone marrow cells only (Daev et al., 2008).

The inhibition of reproduction in the house mouse by DMP could serve as a model of self-regulatory mechanism by which these small animals control their population density and genetic structure through changes at the genome level in germ cells (Fig. 1).

The level of genetic damages which arose after the appearance of some new pheromonal cues (or merely increasing their concentration) reflects the growing genetic heterogeneity of germ cells. In spite of the death of cells with macro-damage and decreased abnormal sperm fertilizing capacity, some of genetically modified sperm are able to fertilize oocytes but this results in embryonic lethality. One could also suggest that some mutations pass through the process of embryonic development and change (or not) some characteristics of their carriers. In any case, the quantity of the progeny of stressed males will be decreased. It seems very probable that the genetic quality of progeny will be changed also, since it was shown earlier that cytogenetic effects of pheromones are genotype-specific, i.e., depend on inbred strains of mice of donor and recipient (Daev, 1994). That effect should disappear at low population density and reappear again as the population density increases. The cytogenetic effects considered here, together with the results of other studies (Daev, 1994, 2007), may demonstrate the work of a pheromonal mechanism of self-regulation of the density and genetic structure of the house mouse populations. Genetic changes induced in germ cells by density-dependent stress-factors such as some pheromones may be of great importance for the microevolutionary process. Our findings are closely connected with the concept of stress as a regulator of biodiversity (Fugere et al., 2012; Gessner and Hines, 2012; Creel et al., 2013) and make evident (at least in mice) the involvement of the genome of germ cells in the process of response to zoosocial stimuli. Thus, usage of our model fills one more gap in our knowledge (Boonstra, 2013) about genome sensitivity to some zoosocial factors and show a possible link between genome destabilization, stress and fitness of populations of mice.

It can be assumed that a similar mechanism may operate in some other species of social animals, preferentially with a well-developed olfactory system.

\section{Acknowledgements}

I thank Dr. S. Rhine for comments on the manuscript and all my colleagues at the Department of Genetics and Biotechnology for their technical assistance with the research.

\section{References}

Adler, I. D. 2000. Spermatogenesis and mutagenicity of environmental hazards: extrapolation of genetic risk from mouse to man. Andrologia 32:233-137. https://doi. org/10.1046/j.1439-0272.2000.00390.x

Adler, I. D., Pacchierotti, F., and Russo A. 2012. The measurement of induced genetic change in mammalian germ cells. Methods in Molecular Biology 817:335-375. https:// doi.org/10.1007/978-1-61779-421-6_16

Amer, S. M., Donya, S. M., and Aly, F. A. E. 2003. Genotoxicity of benomyl and its residues in somatic and germ cells of mice fed on treated stored wheat grains. Archives Toxicology 77:712-721. https://doi.org/10.1007/s00204-0030464-9

Brennan, P.A. and Keverne, E. B. 2004. Something in the air? New insights into mammalian pheromones. Current Biology 14(2):R81-R89. https://doi.org/10.1016/j. cub.2003.12.052

Bronson, F. H. and Coquelin, A. 1980. The modulation of reproduction by priming pheromones in house mice: speculation on adaptive function. In Muller-Schwarze, D. and Silverstein, R. M. (eds), Chemical signals - Vertebrates and aquatic invertebrates, Plenum Press, New York, pp. 243265. https://doi.org/10.1007/978-1-4684-1027-3_16

Brook, J. D. and Chandley, A. C. 1986. Testing for the chemical induction of aneuploidy in the male mouse. Mutation research 164:117-125. https://doi.org/10.1016/01651161(86)90050-6

Bruce, H.M. 1959. An exteroceptive block to pregnancy in the mouse. Nature 184(4680):105. https://doi. org/10.1038/184105a0

Boonstra, R. 2013. The ecology of stress: a marriage of disciplines. Functional Ecology 27:7-10. https://doi. org/10.1111/1365-2435.12048 
Cannon, W. 1935. Stresses and strains of homeostasis. American Journal of the Medical Science 89:1-14. https://doi. org/10.1097/00000441-193501000-00001

Creel, S., Dantzer, B., Goymann, W., and Rubenstein, D. R. 2013. The ecology of stress: effects of the social environment. Functional Ecology 27:66-80. https://doi. org/10.1111/j.1365-2435.2012.02029.x

Daev, E. V. 1983. Action of exogenic metabolites on cytogenetic characteristics of spermatogenesis and reproductive function of house mouse males. PhD thesis, Leningrad State University, Leningrad (Saint-Petersburg). (In Russian)

Daev, E. V. 1994. Pheromonal regulation of genetic processes: research on the house mouse (Mus musculus L.). Russian Journal of Genetics 30(8):964-970.

Daev, E.V. 2003. Induction of dominant lethals in progeny of CBA male mice after pheromonal action. Russian Journal of Genetics 39(10):1138-1142. https://doi. org/10.1023/A:1026122926802

Daev, E. V. 2007. Stress, chemocommunication, and the physiological hypothesis of mutation. Russian Journal of Genetics 43(10):1082-1092. https://doi.org/10.1134/ S102279540710002X

Daev, E. V. 2010. Genetic Aspects of Stress Neuroendocrinology. In Penkava, N. S, and Haight, L. R. (eds), Neuroendocrinology Research Developments. Nova Science Publishers, Inc., New York, Hauppauge, pp. 119-133.

Daev, E. V. and Dukelskaya, A. V. 2003. The female pheromone 2,5-dimethylpyrazine induces sperm-head abnormalities in male CBA mice. Russian Journal of Genetics 39(7):811815. https://doi.org/10.1023/A:1024709321888

Daev, E. V. and Dukelskaya, A. V. 2005. Induction of meiotic disturbances in spermatocytes I by pheromones as an inhibiting mechanism of male reproductive function in house mice. Tsitologiia 47(6):505-509.

Daev, E. V., Surinov, B. P., and Dukelskaya, A. V. 2007. Chemosignaling in CBA and C57Bl/6 mouse strains is modified by stress. Ekologicheskaya Genetika 5(2):37-43. https:// doi.org/10.17816/ecogen5237-43

Daev, E. V., Surinov, B. P., and Dukelskaya, A. V. 2008. Poststress chemosignals affect cells from immunocompetent organs in laboratory mice of three inbred strains Ekologicheskaya Genetika 6(1):27-33. https://doi. org/10.17816/ecogen6127-33

Daev, E.V., Surinov, B.P., Dukelskaya, A. V., and Marysheva, T. M. 2007a. Chromosomal abnormalities and spleenocyte production in laboratory mouse males after exposure to stress chemosignals. Tsitologiia 49(8):696-701.

Daev, E. V., Tzapigina, R. I., and Lopatina, N. G. 1988. Incidence of dominant lethals in the progeny of young male house mice (Mus musculus L.) after exposure to excretory products of mature males of the same species. Genetika 24(11):2015-2021.

Daev, E. V., Vorob'ev, K. V., Shustova, T. I., Zimina, S. A., and Samotokin, M. B. 2000. Genotype-specific changes in functional parameters of immunocompetent cells in laboratory male mice under conditions of pheromoneal stress. Russian Journal of Genetics 6(8):872-876.

Fugere, V., Andino, P., Espinosa, R., Anthelme, F., Jacobsen, D., and Dangles, O. 2012. Testing the stress-gradient hypothesis with aquatic detritivorous invertebrates: insights for biodiversityecosystem functioning research. Journal of Animal Ecology 81:1259-1267. https://doi. org/10.1111/j.1365-2656.2012.01994.x

Gessner, M. O. and Hines, J. 2012. Stress as a modifier of biodiversity effects on ecosystem processes? Journal of Animal Ecology 81:1143-1145. https://doi.org/10.1111/13652656.12011
Glynin, T. S. 2018. Pathways of stabilization and destabilization of bone marrow cell genome under olfactory chemosignals action in mice. PhD thesis in Biology, Saint-Petersubrg State University, Saint-Petersubrg. (In Russian)

Guzzo, A. C., Jheon, J., Imtiaz, F., and DeCatanzaro, D. 2012. Oestradiol transmission from males to females in the context of the Bruce and Vandenbergh effects in mice (Mus musculus). Reproduction 143(4):539-548. https:// doi.org/10.1530/REP-11-0375

Jemiolo, B., and Novotny, M. 1994. Inhibition of sexual maturation in juvenile female and male mice by a chemosignal of female origin. Physiology and Behavior 55(3):519522. https://doi.org/10.1016/0031-9384(94)90110-4

Jha, A. M. and Kumar, M. 2006. In vivo evaluation of induction of abnormal sperm morphology in mice by an unsaturated aldehyde crotonaldehyde. Mutation Research - Genetic Toxicology and Environmental Mutagenesis 603(2):159-163. https://doi.org/10.1016/j.mrgentox.2005.11.010

Kerkis, Y. Y. 1940. Physiologic changes inside cell as a reason of mutation process. Uspehi sovremennoi biologii 1:344350. (In Russian)

Koch, S., Kramer, A., Stein, J., Adrian, V., and Weuffen, W. 1989. Investigation of mutagenicity in sperm-head test/mouse and mutagenic potency of 2 disinfectants on the basis of peracetic acid and phenolics. Zentralblatt fur Hygiene und Umweltmedizin 188(5):391-403.

Koyama, S. 2004. Primer effects by conspecific odors in house mice: a new perspective in the study of primer effects on reproductive activities. Hormones and Behavior 46:303310. https://doi.org/10.1016/j.yhbeh.2004.03.002

Lahdetie, J., Peltonen, K., and Sjoblom, T. 1997. Germ cell mutagenicity of three metabolites of 1,3-butadiene in the rat: induction of spermatid micronuclei by butadiene mono-, di-, and diolepoxides in vivo. Environmental and Molecular Mutagenesis 29:230-239. https://doi. org/10.1002/(SICI)1098-2280(1997)29:3\%3C230::AIDEM2\%3E3.0.CO;2-G

Lawton, A. D., and Whitsett J. M. 1979. Inhibition of sexual maturation by a urinary pheromone in male prairie deer mice. Hormones and Behavior 13(2):128-138. https://doi. org/10.1016/0018-506X(79)90052-7

Lobashev, M. E. 1947. Physiological (paranecrotic) hypothesis of the mutation process. Vestnik Leningradskogo universiteta $8: 10-29$

Ma, W., Miao, Z., and Novotny, M. V. 1998. Role of the adrenal gland and adrenal-mediated chemosignals in suppression of estrus in the house mouse: The Lee-Boot effect revisited. Biology of Reproduction 5(6):1317-1320. https://doi.org/10.1095/biolreprod59.6.1317

Massey, A. and Vandenbergh, J. G. 1980. Puberty delay by a urinary cue from female house mice in feral populations. Science 209:821-822. https://doi.org/10.1126/science.7190728

Massey, A. and Vandenbergh, J. G. 1981. Puberty acceleration by urinary cue from male mice in feral populations. Biology of Reproduction 24:523-527. https://doi.org/10.1095/ biolreprod24.3.523

Oakberg, E. F. 1956. Duration of spermatogenesis in the mouse and timing of stages of the cycle of the seminiferous epithelium. American Journal of Anatomy 99(3):507516. https://doi.org/10.1002/aja.1000990307

Oakberg, E. F. 1957. Duration of spermatogenesis in the mouse. Nature 180:1137-1138. https://doi.org/10.1038/1801137a0

Page, J., Suia, J. A., Santos, J. L., and Rufas, J. S. 1998. Squash procedure for protein immunolocalization in meiotic cells. Chromosome Research 6:639-642. https://doi. org/10.1023/A:1009209628300 
Peele, R., Salazar, I., Mimmack, M., Keverne, E. B., and Brennan, P. A. 2003. Low molecular weight constituents of male mouse urine mediate the pregnancy block effect and convey information about the identity of the mating male. European Journal of Neuroscience 18:622-628. https://doi.org/10.1046/j.1460-9568.2003.02790.x

Rajendren, G. and Dominic, C.J. 1988. Effect of cyproterone acetate on the pregnancy-blocking ability of male mice and the possible chemical nature of the pheromone. Journal of Reproduction and Fertility 84:387-392. https:// doi.org/10.1530/jrf.0.0840387

Selye, H. 1936. A syndrome produced by diverse nocuous agents. Nature 138:32. https://doi.org/10.1038/138032a0

Selye, H. 1946. The general adaptation syndrome and the diseases of adaptation. The Journal of Clinical Endocrinology 6:117-230. https://doi.org/10.1210/jcem-6-2-117
Tirindelli, R., Dibattista, M., Pifferi, S., and Menini, A. 2009. From pheromones to behavior. Physiological Reviews 89:921956. https://doi.org/10.1152/physrev.00037.2008

Tzapigina, R. I., Daev, E. V., and Novikov, S. N. 1981. The influence of excreted metabolites of house mouse males on a cell division process in germ tissue of young animals after single or multiple exposures. The research in genetics 9:17-23.

Vandenbergh, J. G. 1983. Pheromones and reproduction in mammals. Academic Press Inc., New York.

Wyrobek, A.J. and Bruce, W. R. 1978. The induction spermshape abnormalities in mice and humans. In: Hollaender, A. and de Serres, F. J. (eds). Chemicals Mutagen Principles and Methods for their Detectionl 5. Plenum Press, New York, pp. 257-285. 